\title{
Primate communication: Affective, intentional, or both?
}

Heesen R. ${ }^{1}$, Sievers C. ${ }^{2}$, Gruber T. ${ }^{3 \dagger}$, Clay, Z. ${ }^{1 \dagger}$

${ }^{1}$ Department of Psychology, Durham University, UK

${ }^{2}$ Department of Philosophy, York University, Toronto, Canada

${ }^{3}$ Faculty of Psychology and Educational Sciences, and Swiss Center for Affective Sciences, University of Geneva, Switzerland

*Correspondence: zanna.e.clay@durham.ac.uk; raphaela.m.heesen@durham.ac.uk;

${ }^{\dagger}$ Denotes joint-senior authors

This chapter is currently in press and will be published at Cambridge University Press in the volume "Primate Cognitive Studies", edited by Michael J. Beran and Bennett L. Schwartz.

\section{Please use the following citation:}

Heesen R., Sievers C, Gruber T., Clay, Z. (in press). Primate communication: Affective, intentional, or both? In B. L. Schwartz \& M. J. Beran (Eds.), Primate Cognitive Studies. Cambridge University Press. 


\section{Abstract}

The intentional communication of affective states is a central part of human sociality and cognition. Although nonhuman primates (henceforth primates) also signal intentionally, there is a perceived chasm between their intentional versus affective forms of communication. Whereas primate vocalizations and facial expressions are traditionally viewed as involuntary 'read-outs' of affective states, gestures are considered as products of intentional control. However, this traditional view is increasingly contentious, given recent evidence of intentional signal production of primate vocalizations and facial expressions, as well as the general void of arousal-based explanations in gesture research. In this chapter, we challenge the perceived dichotomy between affective and intentional communication in primates and propose a dimensional approach, whereby primate signals can be both affective and intentional, regardless of signal modality (tactile, audible, visible) or component (gesture, facial expression, vocalization). We argue that a dimensional approach, which incorporates both affective and intentional components, would improve our knowledge on how affective and cognitive processes have jointly shaped the evolution of primate communication.

Keywords

Emotion, affect, intentionality, great apes, signaling, emotion communication. 
Primate communication: Affective, intentional, or both?

Natural communication is never entirely devoid of affect, something equally true for humans as well as nonhuman animals (Barrett \& Bliss-Moreau, 2009; Duncan \& Barrett, 2007; Marler, Evans, \& Hauser, 1992). Despite this, human communication has traditionally been held distinct from animal communication, insofar as animal signals were viewed as emotional read-outs of internal states whereas human communication -including languagecould be both affective and referential, i.e., encoding information about objects and events (see Marler \& Evans, 2008; Marler et al., 1992). In a seminal paper, Marler et al. (1992) argued that many ethologists approaching the issue of 'meaning' denote animal signals as either being referential or motivational (i.e., affective), rather than both. Marler et al. argued that such a dichotomy is biologically problematic, given that animal signals may nevertheless function referentially even when proximately driven by affective processes (Marler et al., 1992; Seyfarth \& Cheney, 2003). Despite this important criticism as well as the general progress that has been made in understanding the referential nature of animal signals, current non-human primate research still bears the same mistake, only now with another related concept-intentionality. The affect-intentionality chasm manifests in the view that vocal signals and facial expressions of primates are affective expressions with little intentional control, whereas gestures are by default used intentionally to manipulate receivers (Tomasello, 2008).

More recently, voices in the field of primatology (Graham, Wilke, Lahiff, \& Slocombe, 2019; Kret, Prochazkova, Sterck, \& Clay, 2020; Liebal \& Oña, 2018; Townsend et al., 2017) have returned to question again whether such a dichotomous view of primate communication is biologically meaningful and argue that instead, such views may hamper progress in understanding the proximate and ultimate explanations that shape primate signaling. Two fundamental problems are discussed; the first is that different signal components (i.e. vocal, facial, gestural) are still primarily studied in isolation rather than together as multimodal/multicomponent signal displays, despite the latter being more ecologically valid (Liebal \& Oña, 2018; Liebal, Waller, Slocombe, \& Burrows, 2013; Waller, 
Liebal, Burrows, \& Slocombe, 2013); the second is based on methodological differences in how the underlying mechanisms of signals are even identified, insofar as gestures are identified based on intentionality criteria, whereas vocalizations and facial expressions are identified based on their physical properties (Graham et al., 2019; Townsend et al., 2017). This induces the false impression that intentionality and affect are separable processes that drive different communication modalities.

Conversely, this is not the common consensus in human communication research. Here, it is commonly accepted that humans intentionally communicate about and take into account others' affective states (Barrett \& Bliss-Moreau, 2009; Duncan \& Barrett, 2007). This would suggest that humans, but not nonhuman primates, communicate both affect and intention simultaneously. In humans, for instance, while non-verbal vocalizations such as laughter and crying can carry affective information, words - often combined with prosodic cues- also communicate affective information (e.g., the words' tornado', 'murder', or 'love'), with affect shaping both spoken and signed language systems. This two-way model is possible because humans can (although not always) be consciously aware of their emotional states, meaning we have some control over how we communicate about such states (Ochsner \& Gross, 2005). However, human emotion signals are not always honest (Russell, Bachorowski, \& Fernández-Dols, 2003), insofar as human expressions of emotion via voice, facial or bodily displays and gestures (Banse \& Scherer, 1996; Buck, Losow, Murphy, \& Costanzo, 1992; Dael, Goudbeek, \& Scherer, 2013; Dael, Mortillaro, \& Scherer, 2012; Gross \& Levenson, 1997; Kunzmann, Kupperbusch, \& Levenson, 2005; Scherer, 1986) can be readily modified, suppressed, or exaggerated, such as theatrical acting, when stressing intent, to deceive, enhance cooperation, achieve social goals or to influence a social audience (Batliner, Fischer, Huber, Spilker, \& Nöth, 2000; Kret et al., 2020; Russell et al., 2003; Scherer, 2013). Moreover, research has shown that human participants can reliably distinguish between genuine and posed expressions of emotion, such as laughter, crying and acted emotional speech (Anikin \& Lima, 2018; Juslin, Laukka, \& Bänziger, 2018; Namba, Kabir, Miyatani, \& Nakao, 2018). 
Some scholars have suggested that our capacity for intentional emotion communication, paired with the evolution of greater emotional granularity in the way we construct emotional states (Feldman Barrett, 2017), laid the foundations for the evolution of language (Turner, 1996) as well as for hyper-cooperation and morality (Eisenberg, 2000). Overall, emotions constantly influence our cognition (e.g., decisions, thoughts and plans), and vice-verse cognition also influences our emotions. In this regard, emotions are tightly linked to intentionality (Freeman, 2000). Therefore, human communication naturally carries affective meaning, whether intended by the signaler or perceived as such by the receiver. But what about emotion communication in other animals - could their emotional states be communicated intentionally, and to what extent are primate intentional signals shaped by emotion?

Due to their close phylogenetic relatedness to humans, the great apes represent especially suitable candidates to pursue these questions. The fact that these species also deal with many similar social and ecological problems, including complex group living, suggests that great apes may exhibit some of the hallmarks required for the intentional communication of affective states. Nevertheless, empirical progress in understanding how emotion and cognition interact in shaping primate communication remains under-explored. In part, this is driven by a strong research focus over the past three decades to understanding the referential nature of primate signals (e.g., Townsend \& Manser, 2013). By contrast, the affective content of animal signals has been either ignored or even disregarded, given the wide-held assumption that animals emotions are primarily inaccessible to scientific investigation (see for discussions de Waal, 2011; Panksepp, 2011).

The current chapter aims at discussing these issues and calls to remove the artificial perceived dichotomy of affective versus intention in primate communication. In doing so, we hope to provide a framework for authentic cross-species comparisons on intentionality in emotion communication as well as the influence of affect in shaping intentional communication. Indeed, recent research that shows that even 'emotional' vocalizations, like alarm calls, and facial expressions such as play-faces can be concurrently intentional 
(Crockford, Wittig, Mundry, \& Zuberbühler, 2012; Townsend et al., 2017; Waller, Caeiro, \& Davila-Ross, 2015), and that intentional gestures may be shaped (and possibly even explained) by arousal processes (Graham et al., 2019). Finally, to provide a holistic account of emotion communication in humans and other primates, we contend, like other researchers (Fröhlich, Sievers, Townsend, Gruber, \& van Schaik, 2019; Liebal et al., 2013; Waller et al., 2013), that primate communication research should by default be multimodal (considering all sensory signal channels relevant to primates, notably the visual, acoustic, tactile, and the olfactory channel) as well as multi-componential. The latter implies considering all possible signal components (facial expressions, vocalizations, gestures) as potentially representative of emotional states (Liebal \& Oña, 2018).

In this chapter, building on seminal arguments put forward by Marler and colleagues nearly three decades ago (1992), we discuss progress made in the field to date in exploring the interplay between the intentional and affective bases of primate communication. We concur that several key issues still remain unresolved, such as whether primates possess 'human-like' emotions (Feldman Barrett, 2017), as well as the extent to which primates are capable of intentionally signal production (Graham et al., 2019). Nonetheless, we believe that comparative research into the intentional and affective bases of primate communication cannot advance unless we finally attempt to bridge the perceived chasms related to emotion and cognition. To provide a framework, we will first introduce the perceived gulf between affective and intentional communication in primates and then try to reconcile these views by proposing an affect-cognition framework. Finally, we discuss how dimensional approaches might allow for a more systematic assessment of emotion control across species and thereby inform on the evolution of human language and cognition.

\section{Affective communication in primates}

Although the study of emotions in animals has traditionally been taboo in animal behavior research (for discussions see de Waal, 2011; Panksepp, 2011), it is now growing in momentum and allows for more meaningful comparisons to be drawn with humans (Davila 
Ross, Owren, \& Zimmermann, 2009; Kret et al., 2020). It is important to note here that we use the words emotion and affect interchangeably and that we are not referring to emotions as concepts in the human sense, which, as some authors argue, are constructed via collective intentionality and emotion language (Feldman Barrett et al., 2011). Instead, to allow for meaningful and evolutionarily-grounded cross-species comparisons (Massen et al., 2019), we follow Sander's (2013 p.16) minimal consensus for a definition of emotion: “(1) Emotions are multicomponent phenomena; (2) emotions are two-step processes involving emotion elicitation mechanisms that produce emotional responses; (3) emotions have relevant objects; and (4) emotions have a brief duration compared with other affective phenomena." Emotional responses may involve action tendencies, autonomic reactions, feelings, expressions (communication), perception, memory, attention and decision making (Sander, 2013). We also acknowledge that such internal, affective processes may potentially, similar as in humans, be constructed of bipolar dimensions of hedonic valence (ranging from pleasure-displeasure) and arousal (ranging from sleepy-hyperactivated) (Russell et al., 2003; Duncan and Barrett, 2007). Although the definition of emotions in animals is well beyond the scope of this chapter, we agree with others (Massen et al., 2019) that affective processes and their link to behavior should be studied comparatively by their measurable behavioral or physiological components.

\section{Primary channels expressing affect in primates}

Vocalizations: As well as facial expressions of many species, including primates, vocalizations are assumed to have primarily emotional content (Parr, Waller, \& Vick, 2007; Romanski, Averbeck, \& Diltz, 2005; Waller \& Cherry, 2012). Specifically, comparative behavioral and neuroscience research has suggested that primate vocalizations are hardwired reflections of internal states (Fichtel \& Hammerschmidt, 2003; Hammerschmidt \& Fischer, 2008; Jürgens, Maurus, Ploog, \& Winter, 1967; Owren \& Rendall, 1997; Tomasello, 2008) which are both innate and highly conserved (Geissmann, 1984; Meyer et al., 2012; Thinh, Hallam, Roos, \& Hammerschmidt, 2011). Calls can also carry information about the 
caller, including their relative body size and identity (Rendall et al., 1996). Of most interest for the evolution of human language, primate vocalizations have been shown to provide referential information about the external environment, displaying evidence of functional reference (Seyfarth et al., 1980; Zuberbühler, 2003; Seyfarth and Cheney, 2003), although this has been debated (Scarantino and Clay, 2015; Wheeler and Fischer, 2015). Along with other mammal species (Haney and Miczek, 1993), several primate species have been shown to produce specific vocalizations during agonistic interactions, in particular when experiencing aggression, as documented in rhesus monkeys (Macaca mulatta) (Gouzoules, Gouzoules, \& Marler, 1984) or chimpanzees (Pan troglodytes schweinfurthii) (Slocombe and Zuberbühler, 2005).

These examples are particularly of interest due to the cognitive skills they may reflect. Rhesus monkeys are, for instance, able to make inferences about an ongoing conflict by attending to victim screams (Gouzoules et al., 1984). Similarly, chimpanzees have been shown to produce distinct screams according to their role during agonistic interactions, in which acoustic structure varies depending on whether they are the victim or the aggressor (Slocombe and Zuberbühler, 2005). Screams produced in response to severe aggressions are longer, produced at a higher pitch, and given in longer and slower bouts (Slocombe and Zuberbühler, 2007), consistent with an arousal based explanation (Owren, Amoss, \& Rendall, 2011). Interestingly, victims of aggression appear to have some control over their scream production and are sensitive to audience effects. For instance, chimpanzee victims appear to exaggerate the severity of their screams when bystanders who are higher-ranking than the aggressor are in the audience, suggesting that chimpanzees may strategically modify their calling pattern to recruit help (Slocombe \& Zuberbühler, 2007). Field experiments have also shown that receivers can discriminate between scream variants (Slocombe, Townsend, \& Zuberbühler, 2009) and pay more attention to screams denoting intense aggression than mild aggression. This suggests that screams may serve as a proxy for aggression intensity. Bystanders of social conflicts generally appear to be able to extract meaningful information about the nature of an antagonistic interaction, even though they do 
not witness it directly (Cheney, Seyfarth, \& Silk, 1995; Slocombe, Kaller, Call, \& Zuberbühler, 2010). However, even though chimpanzees seem able to infer emotional states of conspecifics from acoustical signals and adapt their behaviors accordingly, the representational and categorization abilities of chimpanzees that allow them to analyze these calls remain to be investigated (Gruber, Zuberbühler, Clement, \& van Schaik, 2015).

It is possible that the combination of both affective and cognitive processes shaping this kind of calling behavior is supported by brain structures that might be similar to those involved in human non-verbal abilities, as for example has been shown in face processing (Tsao, Moeller, \& Freiwald, 2008). However, being able to analyze the content of the call, such as by determining whether this call is aggressive or affiliative in nature and reacting accordingly, may be rarer among species. Although the reaction to the call may have been shaped by evolution and led to a hard-wired adaptive response, listeners must still be able to selectively discriminate and/or to categorize the emotional content of the call heard, a pragmatic capacity that likely depends on other cognitive mechanisms (Grandjean, Bänziger, \& Scherer, 2006). Such cognitive mechanisms give certain flexibility to the listener to ponder how to reply to the call. As humans, we constantly engage in reasoning and inference-building about our social interactions through attending to communicative signals and surrounding context; and there is strong evidence to suggest that primates do as well (Seyfarth \& Cheney, 2017; Seyfarth et al., 2010). There is further evidence for perceptual categorization of calls (Seyfarth et al., 1980) and the strong role that context plays in shaping their responses, including to referential signals (Crockford, Gruber, \& Zuberbühler, 2018; Scarantino \& Clay, 2015; Slocombe \& Zuberbühler, 2005; Zuberbühler, Cheney, \& Seyfarth, 1999).

Facial expressions: Alone or combined together with vocal cues, the face plays a key role in the emotional communication of humans and other animals. Human facial expressions of emotions are thought to be expressed and understood in a universal manner across cultures (Ekman, 1992), although this stance has justly been debated in recent years as empirical evidence from natural emotion expressions reveal substantial cross-cultural and 
intra-cultural variation (Feldman Barrett, 2017; Scherer, 2013; Siegel et al., 2018).

Compared to high volitional control of human facial expressions, facial expressions in primates are traditionally viewed as inflexible displays of emotion that are under little or no cognitive control, and with an apparently universal cross-species structure (Darwin, 1872).

Primates produce a variety of facial expressions in different contexts, often with strikingly similar forms across species, indicative of homology. For example, the play face exists in most primates and is deployed in solitary as well as social play settings (Demuru, Ferrari, \& Palagi, 2015; Palagi, Antonacci, \& Cordoni, 2007; Palagi, Norscia, \& Spada, 2014; Parr, Cohen, \& Waal, 2005; Waller \& Cherry, 2012). The bared-teeth display, considered a homologue of the human smile, is displayed in negative contexts, although the range of contexts varies across a wide range of primate species (de Waal, 1988; Waller \& Dunbar, 2005; Waller, Whitehouse, \& Micheletta, 2016).

In humans and other primates, facial expressions can be systematically identified via the activation of different muscle action units ( also known as "AUs"), using the Facial Action Coding System (FACS). Since its development nearly 30 years ago, this method has been refined ever since (Ekman, Friesen, \& Hager, 2002) and implies the marking of AU activity, either in real-time or per video recording. Researchers have successfully extended the FACS coding principle for several animal species including chimpanzees ("ChimpFACS", Parr \& Waller, 2006), orangutans ("OrangFACS", Caeiro, Waller, Zimmermann, Burrows, \& Davila-Ross, 2013), macaques ("MaqFACS", Parr, Waller, Burrows, Gothard, \& Vick, 2010), gibbons ("GibbonFACS", Waller, Lembeck, Kuchenbuch, Burrows, \& Liebal, 2012). An interesting aspect underlying the dichotomy central to this chapter is that, although FACS was originally developed to study human emotion, animal FACS are often considered as tools to study animal communication rather than to assess underlying emotional states. One reason may be the strong theoretical impact of the discussion on intentional communication in nonhumans, and the 'competition' between different modalities that occurred therein, as developed in the following section. 


\section{Intentional communication in primates}

In contrast to most views of animal affective communication, intentional communication is by definition voluntary and meaningful, i.e., the producer of a signal intends to provide specific information to an audience. Intentional communication is voluntary in the sense that intentions trigger the signaler to produce the signal rather than a fixed stimulus response. The signal conveys meaning in the sense that the intentions of the signaler determine the signal's meaning, at least from the perspective of the signaler. To be considered intentional, animal signals must meet three essential criteria (Townsend et al., 2017): (1) the signal is goal-oriented, i.e., when the goal is fulfilled, signalers stop producing the signal (Burkart \& van Schaik, 2020); (2) the signal is produced for a specific audience, as evidenced by audience effects; (3) signal production should change the signaler's behavior based on the signaler intended meaning. Note that under the framework of functional reference, the cognitive mechanisms of animal signal production are not assumed. Therefore, there is to some extent a potential disconnect between the receiver's inferred meaning (i.e., the functional referent, such as an alarm call denoting a predator) and the degree of intention on behalf of the signaler.

With regard to animal taxa, intentional communication in accordance to the above described criteria is seen in many species, including primates (e.g., baboons: Bourjade, Meguerditchian, Maille, Gaunet, \& Vauclair, 2014; chimpanzees: Crockford et al., 2012), corvids (Pika \& Bugnyar, 2011), canids (e.g., dogs: Gaunet \& Deputte, 2011; wolfs: Mazzini, Townsend, Virányi, \& Range, 2013) and perhaps even fish (Vail, Manica, \& Bshary, 2013). Additionally, some animal species such as chimpanzees (Andrews, 2012) and dogs (Marshall-Pescini, Ceretta, \& Prato-Previde, 2014) can perceive others (conspecifics and humans) as intentional agents. That is, they understand the behavior of others as goaldirected, which is a necessary requirement for intentional communication.

For a signal to be intentional, it has to be produced with an intention about something, i.e., there is a general aboutness whereby the producer's intentions trigger the signal to be 'about something',( e.g., a mental state of another individual or about something 
in the world), which amounts to the signal's meaning. Dennett (1983) differentiated between various levels of intentional aboutness in his attempt to operationalize animals as intentional systems. Zero-order intentionality attributes no intention to the signaling behavior of animals, whereas first-order intentionality requires the signaler to have an intention about something in the world. For example, 'I believe there is an eagle' is first order because it involves one mental state about something external of the signaler. Second and third-order intentionality involve additional mental states in the signaler of increasing complexity and recursion (e.g., 'I want you to know that there is an eagle in the tree'), involving attributions of mental states to other individuals, i.e., an intention about an intention of the conspecific. In theory, endless levels of intentionality can be displayed, although they are limited by individuals' cognitive abilities. Thus, for a signal to be produced intentionally, intentionality in first or second order is necessary. In humans, intentionally produced signals usually operate at least via secondorder intentionality:

$S$ wants $A$ to know that $p$,

the so-called informative intention. For instance: The signaler wants the audience to know that food is over there.

Interestingly, the mutual exclusion of affect and intentionality in signal production is not perceived as such for the case of human communication. Wharton (2009) showed that both affective and intentional elements can be simultaneously present in human word production, with words also conveying information about affective states. Wharton discusses interjections as examples (Wharton, 2009 p. $70 \mathrm{ff}$.), such as with the case of a child taking an ill-tasting medicine and uttering the interjection "Yuk!". Here, the child expresses an attitude about the world by uttering "Yuk", therefore, generating information that the medicine is ill-tasting. That is, even though the child's use of the word "Yuk" may have been triggered by their affective experience of disgust (and the word's onomatopoeia acoustic structure may be linked to this affective state), the child may have produced the signal intentionally to inform that the medicine is ill-tasting. By contrast, it is also possible that the child did not intend to convey this specific message, but instead intended to voice their general disgust 
(without informing about the ill-tasting medicine) or perhaps did not intend to inform about anything at all, and was instead reflecting uncontrolled affect. In this sense, Wharton argues that the production of such kinds of interjections is both controlled and involuntary to a certain degree. Whether an interjection is produced to inform or produced unintentionally, requires a case- by- case analysis. The recipient, for either case, grasps the information that the medicine is ill-tasting. In conclusion, the role of affect and intention for the interjection's production and meaning are intrinsically tied to each other.

Examples along these lines may be present in other animal species as well: Chimpanzees and bonobos, for instance, produce acoustically distinct food calls that can inform others about different qualities of food (Clay \& Zuberbühler, 2009; Slocombe \& Zuberbühler, 2006). Although acoustic differences in the food calls could directly correlate with the signaler's underlying arousal during feeding, chimpanzees also appear to have a certain degree of control over food call production, and show evidence of intentionality about who they signal to (Schel, Townsend, Machanda, Zuberbühler, \& Slocombe, 2013). Whether it is referential or affective information that is intended to be conveyed (or indeed no intention at all) is difficult to discern, just as it is for the case of human interjections such as the child shouting "Yuk". Furthermore, there appears to be notable flexibility in the production of such signals, even if they are linked to arousal; not in every situation of high arousal does an individual produce a food call. It seems most likely that affect, context, meaning and intention are all intertwined when such signals are produced as well as interpreted by receivers.

\section{Primary channels used to express intentions in primates}

Gestures: Manual, purpose-full movements of limbs, head or the body are considered as primary communicative means for primates to express their intentions (Byrne et al., 2017). Importantly, unlike vocalizations and facial expressions, researchers identify gestures based on intentionality criteria rather than on their physical properties (Call \& Tomasello, 2007; Leavens, Hostetter, Wesley, \& Hopkins, 2004). It is assumed that 
signalers exert some volitional control over gesture production, such as suppressing, exaggerating or otherwise modifying the gesture, or selecting the kind of gesture type to be produced (Leavens, Hostetter, et al., 2004). Some researchers have studied gestures as being separate from body signals, which may also be intentional but involve the movements of the signalers' entire body, rather than manual movements of hands, limbs and head (Heesen, Hobaiter, Ferrer-I-Cancho, \& Semple, 2019). Although the criteria for intentionally differs across studies (Graham et al., 2019), the most common criteria applied in gesture research are; (1) whether signalers take into account the attentional state of the recipient (Liebal, Call, Tomasello, \& Pika, 2004), (2) whether they wait for responses (Hobaiter \& Byrne, 2011a) and (3) whether they persist or elaborate signaling when apparent goals are not met (Hobaiter \& Byrne, 2014). Gestures can be used singly or combined in sequences (Hobaiter \& Byrne, 2011a, 2011b; Liebal, Call, \& Tomasello, 2004) as well as be produced in combination with other signal components and/or multimodally, as combined with auditory sounds, facial expressions and/or species-specific vocalizations, to specify a signaler's social goals (Genty, 2019; Genty, Clay, Hobaiter, \& Zuberbühler, 2014; Genty, Neumann, \& Zuberbühler, 2015; Hobaiter, Byrne, \& Zuberbühler, 2017).

In comparison to vocalizations and facial expressions, which appear to be largely tied to specific contexts (but see Clay et al. 2015), gestures have looser means-to-end mappings insofar as the same gesture may be used in different contexts to achieve diverse social goals (Hobaiter \& Byrne, 2014). Gestures are produced flexibly across contexts including grooming (Pika \& Mitani, 2009), nursing, joint travel (Genty, 2019; Halina, Rossano, \& Tomasello, 2013), play (Fröhlich, Wittig, \& Pika, 2016a) and sexual solicitation (Genty et al., 2015). Different gestures can also be combined with the same, distinct vocalization (e.g., a pout moan or a contest hoot) to communicate different social intentions (Genty, 2019; Genty et al., 2014). Although gesture repertoires and their apparent meanings overlap between different great ape species (Byrne et al., 2017; Graham, Hobaiter, Ounsley, Furuichi, \& Byrne, 2018), there are also notable differences between and within species, with some 
gestures having been apparently learned in development, representing cases of idiosyncrasy (Genty, Breuer, Hobaiter, \& Byrne, 2009).

Gestures also appear to play particularly important roles in coordinating joint activities with conspecifics, including the regulation of putative forms of social commitments and relationships (Heesen et al., 2020), to navigate spontaneous collaboration (Melis \& Tomasello, 2019) and to exchange information in sequences of turn-taking (Fröhlich, Kuchenbuch, et al., 2016). Finally, apes have also been documented to use gestures to convey spatial or referential information to receivers (Hobaiter, Leavens, \& Byrne, 2014; Leavens, Hopkins, \& Bard, 1996), such as to indicate a desired direction of joint travel in contexts of sexual activity (Genty \& Zuberbühler, 2014, 2015). Although the flexibility and frequency by which apes communicate iconic or deictic information may be more restricted than in humans (Genty \& Zuberbühler, 2015), this way of signaling yet represents another parallel between the Pan/Homo communication systems. It also shows that ape gestures can go beyond pragmatic meaning (e.g., to start, resume, continue or stop an interaction: Fröhlich, Wittig, et al., 2016a; Genty et al., 2009; Heesen et al., 2020; Heesen, Genty, Rossano, Zuberbühler, \& Bangerter, 2017; Hobaiter \& Byrne, 2014) to convey spatial meaning, related to an external object or location, to a specific recipient via their morphological form. This may mean primate gestures can qualify as deictic or iconic signals.

Although there has been a heavy bias towards gestures for detecting intentionality criteria in primates, recent studies have shown that some primate vocalizations (Crockford et al., 2018, 2012; Crockford, Wittig, \& Zuberbühler, 2015; Gruber \& Zuberbühler, 2013; Schel et al., 2013), voiced sounds (Hopkins, Taglialatela, \& Leavens, 2011) and facial expressions (Waller et al., 2015) can also meet the same intentionality criteria required for gestures (Crivelli \& Fridlund, 2018). For example, vocalizations, sounds and facial expressions can be modified to the attentional state of the recipient (Demuru et al., 2015; Hopkins et al., 2011; Leavens, Hostetter, et al., 2004; Waller et al., 2015), to the audience composition and activity type (Flack, Jeannotte, $\&$ de Waal, 2004), as well as to inform receivers of imminent danger in highly arousing, predatory contexts (Crockford et al., 2012). Some recent studies 
showed that wild chimpanzees take into account the knowledge state of their receiver before producing alarm calls, providing evidence of intentional call production - a topic which we will discuss in detail in the following section (Crockford et al. 2012; Schel et al., 2013). For facial expressions, gibbons have been shown to increase the duration and intensity of their facial expressions in social settings, i.e., when facing another partner versus when not (Scheider, Waller, Oña, Burrows, \& Liebal, 2016). Play faces in bonobos and chimpanzees can also be adjusted to the age of the playmate, and on the presence of relevant audience members (Cordoni \& Palagi, 2011; Flack et al., 2004), as well as depending on the play type and the recipient's attentive state (Demuru et al., 2015). These new lines of evidence suggest that both facial expression and vocalizations can involve intentional properties in similar ways as gestures (Graham et al., 2019; Townsend et al., 2017).

Towards an affective-cognitive dimensional approach to study primate communication Thus far, our review has highlighted some crucial aspects about the apparently problematic assumption of emotionality and intentionality being dissociable in different modes of primate communication. Some scholars have traditionally viewed primate vocalizations and facial expressions as honest signals (i.e., those that directly reflect the signaler's underlying internal state) that are inflexible and involuntary responses to certain events lacking cognitive control (Ekman, 1992; Owren \& Rendall, 1997; Tomasello, 2008), and that intentionality or goal-directedness is mainly reserved for manual gestures or body signals (Call \& Tomasello, 2007). However, as noted, this distinction is under threat because of growing evidence suggesting intentional use of vocalizations and facial expressions (Crockford et al., 2012; Hopkins et al., 2011; Scheider et al., 2016; Schel et al., 2013; Townsend et al., 2017; Waller et al., 2015), as well as a lack of discussions on possible affect-based explanations for prevalence of intentional signals like gestures (Graham et al., 2019). The latter is especially evident as some gestures and body signals can indeed, like vocalizations and facial expressions, be used in high-arousal contexts such as conflicts or rough social play (Brooker, Webb, \& Clay, 2020; Genty et al., 2009, 2015; Heesen et al., 
2019; Hobaiter \& Byrne, 2012). In sum, research on primate intentionality frequently bypasses the role that arousal and valence play in communication (Barrett \& Bliss-Moreau, 2009; Duncan \& Barrett, 2007; Tamir, Thornton, Contreras, \& Mitchell, 2016). For instance, one criterion used to identify intentional signals in nonhuman primates is the persistence in signaling if the receiver has not reacted in ways satisfying to the signaler (Leavens, Russell, \& Hopkins, 2005). Thus, take a situation in which a signaler continuously produces a baredteeth expression to a more dominant individual and only stops to show this facial expression after having been consoled by a more dominant receiver (e.g., Graham et al., 2019). Gesture research would denote this as intentional (Leavens et al., 2005) even though the expression might actually be explained by arousal, such as owing to the presence of a social audience or more dominant audience members (Zajonc, 1965). Of course, arousal may also explain audience effects for vocalizations, which have been previously suggested to reflect cognitive awareness (Zuberbühler, 2008).

Nonetheless, signalers might be able to control their expressions despite their high arousal state. Evidence supporting this point is that apes readily modify the acoustic structure of their vocalizations in respect to the presence or knowledge state of certain audience members (Crockford et al., 2012; Fedurek, Slocombe, \& Zuberbühler, 2015; Slocombe \& Zuberbühler, 2007). For example, some chimpanzee alarm calls (Crockford et al., 2012; Schel et al., 2013) were assessed for intentionality over subsequent study periods using the same method, but with contradictory results: in one study (Schel et al., 2013), the experimenters presented a moving snake model to wild chimpanzees, to which some chimpanzees responded with alert hoos as immediate response to the to the moving snake model, often without being influenced by an arriving audience, or if an audience was present accompanied by little audience checking. The authors concluded that the calls would best be described as zero-order intentional (Schel et al., 2013). In a different study on same chimpanzee community, experimenters presented a static snake model, to which the chimpanzee produced alert hoos, but in this case with tactic deployment and in respect with the recipients state of knowledge (Crockford et al., 2012) - meaning the signaler persisted 
until the audience members knew that there was a snake. Whereas the study of Schel et al. would have suggested that alert hoos are emotional (i.e., zero-order intentional), the study by Crockford et al. would have led to the conclusion that this type of vocalization can be used second-order intentionally.

Although it is unclear what caused the conflicting findings, the example nonetheless demonstrates that the same signals are potentially driven by both affect- and intention depending on the circumstance, like the level of risk involved, as implied by the moving or static snake model (see Graham et al., 2019; and Schel et al., 2013 for detailed discussions on this point). This is also the case in humans, for instance, in which control of language may be lost in settings of extreme emotion (e.g., swearing in a traffic jam). Such signals might be identified as intentional but are in reality evoked by arousal, and that the same signals tagged as emotional can in fact be used intentionally in certain circumstances.

It appears falsely reductionist, therefore, to extrapolate that all vocalizations are affect-driven, and all gestures are intentional (Maiese, 2014). Naturally, some speciesspecific emotion expressions may indeed be less controllable than others. But it creates a bias to discriminate signals as affective versus intentional. Instead, it may be best to consider that signals can be both, where the degree of control might depend on the social or physical context, audience size and composition, previous events, the signaler's current affective state, its age, rearing and status in a group. All these factors may influence dimensions of how we would perceive the signal on the scale of affect and volitional control. We thus agree with Graham et al. (2019) that it is problematic to extrapolate intentionality to all types of signals if only one type follows intentionality criteria (i.e., as in, 'since some gesture types follow intentionality criteria, gestures are produced intentionality"). A more realistic approach would be to first assess dimensions of affect and intentionality for each signal type, and on an event-by-event basis, with careful consideration of any factor possibly affecting signalers' arousal and emotional valence (see Figure 1 in Gruber \& Grandjean, 2017). 
To circumvent inaccurate groupings of signal components into binary categories, we propose a dimensional approach to study primate communication (Figure 1). A dimensional approach can be useful, because it avoids potential biases in the way primate signaling is being analyzed, and builds a more realistic, holistic picture of signaling complexity and the interplay between emotion and intention. Such a method also allow more systematic assessment of primate signaling. It acknowledges the possibility that although one vocalization type, like the victim scream (Pollick \& De Waal, 2007), might involve less volitional control than another, e.g., the alert or travel hoo (Crockford et al., 2018; Gruber \& Zuberbühler, 2013), but while taking account of the valence and arousal states. In other words, it avoids generalizations of intentionality (or emotionality) over signal components (vocalizations, gestures, facial expressions). Such comparisons are also needed for the comparative assessment of emotion control with humans, and might be fruitful for theories of language evolution, as we will discuss below.

Figure 1 demonstrates the dimensional framework based on the use of three signals included in the communicative repertoire of chimpanzees. The dimensional chart displays the presumed level of intentional control involved in the use of distinct signal types as a function of arousal and valence. In doing so, it demonstrates the possibility that arousal plays a complementary role to intentional processes, as it does in humans (Graham et al., 2019; Wharton, 2009). Figure 1 is a matrix by which affect-cognition dimensions of signal types can be categorized as a function of the signal's fulfilled intentionality criteria (0/3: None fulfilled, signal was used without presence of social audience; 1-3/3: One, two or all three intentionality criteria fulfilled including audience checking/sensitivity, response waiting, and persistence/elaboration) and presumed basis of arousal (low-extreme). The valence can be indicated with a color scheme, with red for negative, green for positive and grey for neutral valence of the context in which the signal was produced.

But how can we assess arousal? Although intentionality can be assessed based on signaler behavior, arousal is more difficult to measure. Previous work has used physiological approaches such as measuring excretion of the glucocorticoid hormones, associated with 
stress and arousal (Wheeler, Tiddi, \& Heistermann, 2014). Other noninvasive methods such as infrared-thermography (IRT) allow for further measuring physiological arousal responses. IRT is a contact free method that allows for measuring the facial skin temperature changes caused by the peripheral blood flow which is controlled by the autonomic nervous system (ANS) (loannou, Gallese, \& Merla, 2014; Tattersall, 2016). Previous research already successfully applied thermal imaging in primates (Kano, Hirata, Deschner, Behringer, \& Call, 2016), even in the wild (Dezecache, Zuberbühler, Davila-Ross, \& Dahl, 2017). We note, however, that one should be careful in the interpretation of results when images are taken outside and when primates are within their social group, as this method is extremely sensitive to environmental factors like sun, humidity and the presence of other bodies or objects (Tattersall, 2016).

Another useful indicator, although less objective and currently dependent on human rating, is piloerection. Primates, like other mammals, experience a bristling of the body hair due to the skin being erected through physiological arousal (Benedek \& Kaernbach, 2011; Chaplin, Jablonski, Sussman, \& Kelley, 2014). The phenomenon of piloerection is by default involuntary, as controlled by the ANS, and reflects the emotional arousal state of the animal (Benedek \& Kaernbach, 2011). Thus far, piloerection has been observed in the copulatory acts of wild chimpanzees (Nishida, 1997) and represents a promising non-invasive video coding method if images can be collected of suitable quality.

A last resort to assess arousal is by assumptions about the context itself, although this remains largely speculative and should be backed up by physiology data before drawing firm conclusions. Previous physiological research has shown that that conflict aggression, agonistic vocalizations of others, events of attack by predator and sexual interactions are highly arousing (Dezecache et al., 2017; Kano et al., 2016; Nishida, 1997). Similarly, contexts involving intense, rough, or intimate bodily contact such as grooming, play, nursing, or those involving some degree of tension or insecurity like feeding, could generally be considered to evoke medium to high levels of arousal. This is because they concur risks as of potential for escalation and aggression (feeding competition: Hanya 2009; Robbins 2008; 
social play: Smith and Boulton 1990; Pellis and Pellis 1996; Palagi et al. 2015), as they involve treatment of sensitive body parts (grooming: Fedurek, Slocombe, Hartel, \& Zuberbühler, 2015), or intense/rough body contact (social play: Flack et al., 2004; Heesen et al., 2017). Other general state behaviors, such as sleeping, resting, as well as neutral dyadic interactions like sitting in close proximity or travelling together, could perhaps be seen as neutral contexts involving low or slight arousal states, as these contexts involve low risks; indeed these contexts primarily involve types of neutral facial expressions (closed-mouth or relaxed-lip face), which are often used as neutral baseline stimuli in primate emotion research (Parr, 2001; Parr et al., 2005; Parr, Hopkins, \& DeWaal, 1998; Parr, Waller, \& Heintz, 2008). Using this matrix (Figure 1), we now demonstrate the affect-cognition dimensions of three signal components (vocalization, facial expression, gesture) used in chimpanzees.

Vocal communication (Figure 1 A): As explained above, chimpanzee alert hoos provide a good example that demonstrates intentionality in relation to arousal. Chimpanzees produce such calls in response to a predatory event, both without the presence of an audience, suggesting zero-order intentionality (Schel et al., 2013) as well as to inform ignorant group members, suggesting second-order intentionality (Crockford et al., 2012). Because snakes are often approached by chimpanzees and do not seem to represent extreme danger to chimpanzees (Crockford et al., 2012; Schel et al., 2013), Figure $1 \mathrm{~A}$ categorizes the usage of this vocalization in a medium (snake static; Crockford et al., 2012) and highly (snake moving; Schel et al., 2013) arousing negative context, and with varying control over the production. As said, the causes of the variance in control are yet to be identified.

Facial communication (Figure 1 B): Play faces in chimpanzees can be adapted to the identity and the attentive state of the partner, as well as to the type, intensity and stage of play (Cordoni \& Palagi, 2011; Davila-Ross, Jesus, Osborne, \& Bard, 2015) and the 
presence of certain audience members outside of the dyadic interaction (Flack et al., 2004). Play faces also facilitate the maintenance of play, evidenced by the fact that play bouts are longer if play mates exhibit play faces (Waller \& Dunbar, 2005). Thus, the play face fulfills at least the intentionality criterion based on social use (i.e., audience effects), manifested by the sensitivity to the attention of receivers. However, as the play face equally appears when engaging in solitary play (Cordoni \& Palagi, 2011), it can also be deployed without intentionality and as a response to positive arousal alone. To our knowledge, there is no clear evidence that play faces can be used and be followed by gaps of response waiting, or to be repeated in initiations of play when the partner is not responding appropriately. Therefore, the dimension chart would position play faces in chimpanzees to appear in positive valence contexts, spanning medium and highly arousing states due to its presence in solitary, gentle and rough social play, respectively. Social use and audience sensitivity (1 of 3 intentionality criteria) were found only in gentle and rough social play (Figure $1 \mathrm{~B}$ ). More research is needed however, ideally applying psycho-physiological techniques in order to disentangle the interplay between arousal, valence and intentionality seen for play faces.

Gestural communication (Figure $1 \mathrm{C}$ ): The third example is based on a reach gesture in chimpanzees, defined as reaching towards the recipient/s by extending the arm and hand, palm upwards or downwards, or wrist, sometimes referred to as 'begging' or 'extend hand/arm/wrist' (see Byrne et al., 2017). In chimpanzees, as in other great ape species (Byrne et al., 2017), the reach gesture has been identified as first-order intentional. It is produced across a wide range of contexts of differing valence (positive, neutral, negative), and regardless of context or arousal, is always produced in presence of a social audience with signalers being attentive to the recipients' attention (Hobaiter \& Byrne, 2011b; Hostetter, Cantero, \& Hopkins, 2001; Leavens, Hopkins, \& Thomas, 2004; Leavens, Hostetter, et al., 2004). Although the social use of reach has been described for high arousal negative valence contexts, namely aggression (Pollick \& De Waal, 2007), to our knowledge no systematic assessments of other intentionality rules have been conducted in such 
contexts, see Figure $1 \mathrm{C}$. As for all other contexts, response waiting and persistence have been documented for reach (Graham et al., 2018; Hobaiter \& Byrne, 2011a, 2011b, 2014; Leavens et al., 2005). Reach is thus being used with first-order intentionality across all contexts spanning neutral to positive valence and possibly across all arousal states (except extreme arousal, where not all intentionality criteria have been applied, see Figure $1 \mathrm{C}$ ). Medium-high arousal states of negative valence might include contexts such as food or object begging, as the signaler is attempting to acquire a resource (Fröhlich, Müller, Zeiträg, Wittig, \& Pika, 2020; Leavens et al., 2005), or sexual solicitation in courtship scenarios (Graham et al., 2018; Hobaiter \& Byrne, 2012). We note, however, that valence for food begging is difficult to determine without physiological data, but because it is often accompanied by other emotion expressions indicating negative arousal (e.g., bared-teeth), it might best be defined as negative/tense context. Medium-high arousal states of positive valence might include gentle or rough play bouts, in which reach is often used to solicit others for play (Fröhlich, Wittig, et al., 2016a). Reach gestures can also be used intentionally in low arousing settings such as when to climb on (or be climbed on by) others, get into bodily contact, or joint travel (Fröhlich, Wittig, \& Pika, 2016b; Graham et al., 2018).

Although all these studies mentioned above (except Pollick \& De Waal, 2007) have applied all of the three intentionality criteria (audience checking, response waiting, persistence/elaboration) to identify the reach gesture (among others), not all of the cited studies have specified whether all of the three criteria had to be met, or whether only one was sufficient. This is a common problem in research that identifies intentional behavior in primates: The intentionality criteria are used variably in both number and definition (Graham et al., 2019), calling for a more systematic assessment. 

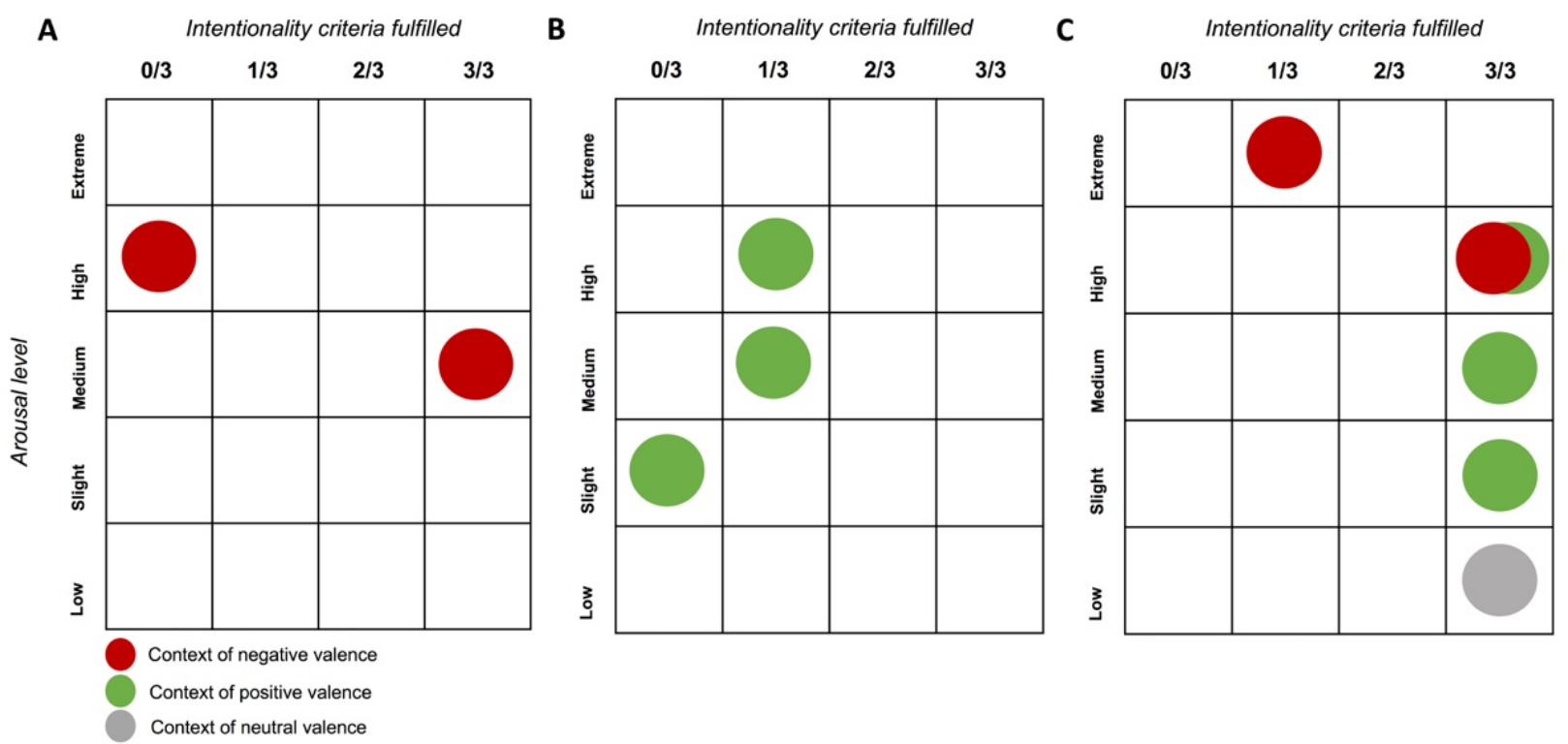

Fig. 1. Attempt at summarizing the current state of the art on communicative control and (presumed) arousal involved in the use of the alert hoo vocalization (A), the play face expression (B) and reach gesture (C) used by chimpanzees.

\section{Implications of the dimensional approach}

As shown in Figure 1, some signal types seem to span a wider breadth of arousal, valence states, and intentionality criteria than others. Although we have only discussed three signal types of each component, our examples show that these examples of gestures and vocalizations can reach higher orders of intentionality (Crockford et al., 2012; Townsend et al., 2017), whereas the facial expression we selected only fulfilled the criteria of social use, i.e., in response to the presence and attentive state of an audience. It is possible that other facial expressions fulfill criteria of response waiting and persistence, but this cannot be decided here and should be addressed in future studies. Moreover, it is evident that the reach gesture spans a broad range of valence and presumed arousal states, whereas the alert hoo is tightly linked to one valence and more restricted arousal states. These examples fit with the general hypothesis that gestures are used more flexibly in terms of contextual specificity as compared to vocalizations and facial expressions (Call \& Tomasello, 2007). 
However, the matrix indicates the affective-cognitive dimensionality of each signal, rather than reducing them to an artificial dichotomy (Demuru et al., 2015; Liebal \& Oña, 2018 for similar arguments; e.g., see also Maiese, 2014). This approach allows for a more granular assessment of emotion control in primate communication. Even though arousal measures were not assessed here and are difficult to implement in wild animals, we hope that future research can further develop this framework via the appliance of psycho-physiological techniques.

The framework might also help in more directly testing theories on language evolution. Because language does not fossilize, comparative research is thus pivotal for the reconstruction of possible evolutionary pathways of linguistic communication and the role of emotion in its evolution. One theory (Turner, 1996) suggests that, due to the increased need for social bonding, efficient hunting and predator protection in Savannah habitats, control of emotion expressions proved useful for our ancestors, such as for enhancing cooperation and empathy but also for social deception (where expressions can be used strategically), as well as more flexible hunting and anti-predator strategies. Such control (perhaps starting off with the suppression of emotion expressions) supposedly preceded the evolution of language itself, and then, through the use of language, reached more sophisticated forms and allowed for more complex emotion functions in modern human communication (Turner, 1996). Indeed, humans are able to communicate emotions in controlled ways, to consciously experience and reflect upon a huge variety of emotional states (Feldman Barrett, 2017), to rely on emotion cues when reading others' behaviors (Kret, 2015), and to intentionally communicate to suppress, modify or exaggerate emotions across a wide array of social contexts (Turner, 1996). Additionally, emotion perception via nonlinguistic, automatic cues (like pupil dilation and pupil mimicry) are intrinsic to cooperative interactions in humans and social decision making (Behrens \& Kret, 2019; Behrens et al., 2019; Massen et al., 2019).

\section{Conclusion and future directions}


Nearly thirty years ago, Marler et al. (1992) posed the question- 'Are animal signals motivational, referential or both?'. Since this time, there has been much debate surrounding the roles that affect and cognition play in shaping primate communication and much empirical progress, including the birth of gesture research, which has substantially advanced our understanding of primate communication. While Marler and colleagues (1992) argued that animal signals can display both properties, there has continued to be a long-held view that primate vocalizations and facial expressions are inherently affective whereas gestures are primarily intentional. Our review here suggests that such assumptions may be inaccurate and underestimate the overlap in affective and cognitive processes which shape primate signaling overall. Rather than imposing a false dichotomy between affect and cognition, the affective-cognitive dimensional approach, as presented above, provides an alternative framework that acknowledges the dual role of affect and cognition in shaping animal signaling, which may help to better identify the level of control involved in the communication of emotions in both humans and animals. Indeed, vocalizations can be produced in a presumably arousing state both with and without intentional control, constituting promising evidence for contextually-variable degrees of emotion control. Such findings provide promising new insights into the emotion capacities of primates (Berlo, Bionda, \& Kret, 2020), and give rise to exciting, novel future avenues for comparative affective and cognitive science to unravel the puzzle of the evolution of human language and cognition. Future research should seek to more closely integrate the role that different signaling channels play in the expression of emotion in primates, by viewing primate communication as a holistic multimodal system that comprises multiple related but distinct components that dynamically interact. A further important direction to aid scientific progress is the integration of behavioral and neural approaches to identify both the neural and behavioral correlates of emotion expression in animals. Promising steps are now being taken in non-invasive approaches to investigating the underlying physiology shaping primate communication. We argue that a multi-dimensional and multimodal approach is needed to advance our understanding of the affective and cognitive basis of primate communication. 


\section{References}

Andrews, K. (2012). Do apes read minds? : toward a new folk psychology. MIT Press.

Anikin, A., \& Lima, C. F. (2018). Perceptual and acoustic differences between authentic and acted nonverbal emotional vocalizations. Quarterly Journal of Experimental Psychology (2006), 71(3), 622-641. https://doi.org/10.1080/17470218.2016.1270976

Banse, R., \& Scherer, K. R. (1996). Acoustic profiles in vocal emotion expression. Journal of Personality and Social Psychology, 70(3), 614-636. https://doi.org/10.1037/00223514.70.3.614

Barrett, L. F., \& Bliss-Moreau, E. (2009). Affect as a psychological primitive. Advances in Experimental Social Psychology, 41, 167-218. https://doi.org/10.1016/S00652601(08)00404-8

Batliner, A., Fischer, K., Huber, R., Spilker, J., \& Nöth, E. (2000). Desperately seeking emotions: actors, wizards, and human beings. In Proc. ISCAWorkshop on Speech and Emotion (pp. 195-200). Newcastle, Northern Ireland.

Behrens, F., \& Kret, M. E. (2019). The Interplay Between Face-to-Face Contact and Feedback on Cooperation During Real-Life Interactions. Journal of Nonverbal Behavior, 43(4), 513-528. https://doi.org/10.1007/s10919-019-00314-1

Behrens, F., Snijdewint, J. A., Moulder, R. G., Prochazkova, E., Sjak-Shie, E. E., Boker, S. M., \& Kret, M. E. (2019). Physiological synchrony promotes cooperative success in real-life interactions. BioRxiv, 792416. https://doi.org/10.1101/792416

Benedek, M., \& Kaernbach, C. (2011). Physiological correlates and emotional specificity of human piloerection. Biological Psychology, 86(3), 320-329.

https://doi.org/10.1016/J.BIOPSYCHO.2010.12.012

Berlo, E. van, Bionda, T., \& Kret, M. E. (2020). Attention Towards Emotions is Modulated by Familiarity with the Expressor. A Comparison Between Bonobos and Humans. BioRxiv, 2020.05.11.089813. https://doi.org/10.1101/2020.05.11.089813

Bourjade, M., Meguerditchian, A., Maille, A., Gaunet, F., \& Vauclair, J. (2014). Olive baboons, Papio anubis, adjust their visual and auditory intentional gestures to the visual 
attention of others. Animal Behaviour, 87, 121-128.

https://doi.org/10.1016/J.ANBEHAV.2013.10.019

Brooker, J. S., Webb, C. E., \& Clay, Z. (2020). Fellatio among male sanctuary-living chimpanzees during a period of social tension. Behaviour, 158(1), 77-87. https://doi.org/10.1163/1568539x-bja10053

Buck, R., Losow, J. I., Murphy, M. M., \& Costanzo, P. (1992). Social facilitation and inhibition of emotional expression and communication. Journal of Personality and Social Psychology, 63(6), 962-968. https://doi.org/10.1037/0022-3514.63.6.962

Burkart, J. M., \& van Schaik, C. P. (2020). Marmoset prosociality is intentional. Animal Cognition, 23(3), 581-594. https://doi.org/10.1007/s10071-020-01363-6

Byrne, R. W., Cartmill, E., Genty, E., Graham, K. E., Hobaiter, C., \& Tanner, J. (2017). Great ape gestures: intentional communication with a rich set of innate signals. Animal Cognition, 20(4), 755-769. https://doi.org/10.1007/s10071-017-1096-4

Caeiro, C. C., Waller, B. M., Zimmermann, E., Burrows, A. M., \& Davila-Ross, M. (2013). OrangFACS: A muscle-based facial movement coding system for orangutans (Pongo spp.). International Journal of Primatology, 34(1), 115-129.

https://doi.org/10.1007/s10764-012-9652-x

Call, J., \& Tomasello, M. (2007). The gestural communication of apes and monkeys. Mahwah, New Jersey: Lawrence Erlbaum Associates.

Chaplin, G., Jablonski, N. G., Sussman, R. W., \& Kelley, E. A. (2014). The role of piloerection in primate thermoregulation. Folia Primatologica, 85(1), 1-17. https://doi.org/10.1159/000355007

Cheney, D. L., Seyfarth, R. M., \& Silk, J. B. (1995). The responses of female baboons (Papio cynocephalus ursinus) to anomalous social interactions: Evidence for causal reasoning? Journal of Comparative Psychology, 109(2), 134-141. https://doi.org/10.1037/0735-7036.109.2.134

Clay, Z., Archbold, J., \& Zuberbühler, K. (2015). Functional flexibility in wild bonobo vocal behaviour. PeerJ, 3, e1124. https://doi.org/10.7717/peerj.1124 
Clay, Z., \& Zuberbühler, K. (2009). Food-associated calling sequences in bonobos. Animal Behaviour, 77(6), 1387-1396. https://doi.org/10.1016/J.ANBEHAV.2009.02.016

Cordoni, G., \& Palagi, E. (2011). Ontogenetic trajectories of chimpanzee social play:

Similarities with humans. PLoS ONE, 6(11), e27344.

https://doi.org/10.1371/journal.pone.0027344

Crivelli, C., \& Fridlund, A. J. (2018). Facial displays are tools for social influence. Trends in Cognitive Sciences, 22(5), 388-399. https://doi.org/10.1016/J.TICS.2018.02.006

Crockford, C., Gruber, T., \& Zuberbühler, K. (2018). Chimpanzee quiet hoo variants differ according to context. Royal Society Open Science, 5(5), 172066.

https://doi.org/10.1098/rsos.172066

Crockford, C., Wittig, R. M., Mundry, R., \& Zuberbühler, K. (2012). Wild chimpanzees inform ignorant group members of danger. Current Biology, 22(2), 142-146.

https://doi.org/10.1016/j.cub.2011.11.053

Crockford, C., Wittig, R. M., \& Zuberbühler, K. (2015). An intentional vocalization draws others' attention: A playback experiment with wild chimpanzees. Animal Cognition, 18(3), 581-591. https://doi.org/10.1007/s10071-014-0827-z

Dael, N., Goudbeek, M., \& Scherer, K. R. (2013). Perceived gesture dynamics in nonverbal expression of emotion. Perception, 42(6), 642-657. https://doi.org/10.1068/p7364

Dael, N., Mortillaro, M., \& Scherer, K. R. (2012). Emotion expression in body action and posture. Emotion, 12(5), 1085-1101. https://doi.org/10.1037/a0025737

Darwin, C. (1872). The expression of the emotions in man and animals (2nd ed.). London: John Murray.

Davila-Ross, M., Jesus, G., Osborne, J., \& Bard, K. A. (2015). Chimpanzees (Pan troglodytes) produce the same types of 'laugh faces' when they emit laughter and when they are silent. PLOS ONE, 10(6), e0127337. https://doi.org/10.1371/journal.pone.0127337

Davila Ross, M., Owren, M. J., \& Zimmermann, E. (2009). Reconstructing the evolution of laughter in great apes and humans. Current Biology, 19(13), 1106-1111. 
https://doi.org/10.1016/j.cub.2009.05.028

de Waal, F. B. M. (1988). The communicative repertoire of captive bonobos (Pan paniscus), compared to that of chimpanzees. Behavior, 106(3), 183-251.

https://doi.org/https://doi.org/10.1163/156853988X00269

de Waal, F. B. M. (2011). What is an animal emotion? Annals of the New York Academy of Sciences, 1224(1), 191-206. https://doi.org/10.1111/j.1749-6632.2010.05912.x

Demuru, E., Ferrari, P. F., \& Palagi, E. (2015). Emotionality and intentionality in bonobo playful communication. Animal Cognition, 18(1), 333-344.

https://doi.org/10.1007/s10071-014-0804-6

Dennett, D. C. (1983). Intentional systems in cognitive ethology: The "Panglossian paradigm" defended. Behavioral and Brain Sciences, 6(3), 343-355. https://doi.org/10.1017/S0140525X00016393

Dezecache, G., Zuberbühler, K., Davila-Ross, M., \& Dahl, C. D. (2017). Skin temperature changes in wild chimpanzees upon hearing vocalizations of conspecifics. Royal Society Open Science, 4(1), 160816. https://doi.org/10.1098/rsos.160816

Duncan, S., \& Barrett, L. F. (2007). Affect is a form of cognition: A neurobiological analysis. Cognition \& Emotion, 21(6), 1184-1211. https://doi.org/10.1080/02699930701437931 Eisenberg, N. (2000). Emotion, Regulation, and Moral Development. Annual Review of Psychology, 51(1), 665-697. https://doi.org/10.1146/annurev.psych.51.1.665

Ekman, P. (1992). An argument for basic emotions. Cognition and Emotion, 6(3-4), 169200. https://doi.org/10.1080/02699939208411068

Ekman, P., Friesen, W. V, \& Hager, J. C. (2002). Facial Action Coding System. Salt Lake City, USA: Research Nexus.

Fedurek, P., Slocombe, K. E., Hartel, J. A., \& Zuberbühler, K. (2015). Chimpanzee lipsmacking facilitates cooperative behaviour. Scientific Reports, 5(1), 13460. https://doi.org/10.1038/srep13460

Fedurek, P., Slocombe, K. E., \& Zuberbühler, K. (2015). Chimpanzees communicate to two different audiences during aggressive interactions. Animal Behaviour, 110, 21-28. 
https://doi.org/10.1016/J.ANBEHAV.2015.09.010

Feldman Barrett, L. (2017). How emotions are made: The secret life of the brain. New York: Houghton Mifflin Harcourt.

Feldman Barrett, L., Barsalou, L., Fugate, J., Lindquist, K., Mesquita, B., Nie-Denthal, P., ... Barrett, F. (2011). Emotions Are Real, 0-000. https://doi.org/10.1037/a0027555

Fichtel, C., \& Hammerschmidt, K. (2003). Responses of squirrel monkeys to their experimentally modified mobbing calls. The Journal of the Acoustical Society of America, 113(5), 2927-2932. https://doi.org/10.1121/1.1548158

Flack, J. C., Jeannotte, L. A., \& de Waal, F. (2004). Play signaling and the perception of social rules by juvenile chimpanzees (Pan troglodytes). Journal of Comparative Psychology, 118(2), 149-159. https://doi.org/http://dx.doi.org/10.1037/07357036.118.2.149

Freeman, W. J. (2000). Emotion Is Essential to All Intentional Behaviors. In Emotion, Development, and Self-Organization (pp. 209-235). Cambridge University Press. https://doi.org/10.1017/CBO9780511527883.010

Fröhlich, M., Kuchenbuch, P., Müller, G., Fruth, B., Furuichi, T., Wittig, R. M., \& Pika, S. (2016). Unpeeling the layers of language: Bonobos and chimpanzees engage in cooperative turn-taking sequences. Scientific Reports, 6(25887), 25887. https://doi.org/10.1038/srep25887

Fröhlich, M., Müller, G., Zeiträg, C., Wittig, R. M., \& Pika, S. (2020). Begging and social tolerance: Food solicitation tactics in young chimpanzees (Pan troglodytes) in the wild. Evolution and Human Behavior, 41(2), 126-135.

https://doi.org/10.1016/J.EVOLHUMBEHAV.2019.11.002

Fröhlich, M., Sievers, C., Townsend, S. W., Gruber, T., \& van Schaik, C. P. (2019).

Multimodal communication and language origins: integrating gestures and vocalizations. Biological Reviews, 94(5), 1809-1829. https://doi.org/10.1111/brv.12535

Fröhlich, M., Wittig, R. M., \& Pika, S. (2016a). Play-solicitation gestures in chimpanzees in the wild: flexible adjustment to social circumstances and individual matrices. Royal 
Society Open Science, 3(8). https://doi.org/10.1098/rsos.160278

Fröhlich, M., Wittig, R. M., \& Pika, S. (2016b). Should I stay or should I go? Initiation of joint travel in mother-infant dyads of two chimpanzee communities in the wild. Animal Cognition, 19(3), 483-500. https://doi.org/10.1007/s10071-015-0948-z

Gaunet, F., \& Deputte, B. L. (2011). Functionally referential and intentional communication in the domestic dog: effects of spatial and social contexts. Animal Cognition, 14(6), 849860. https://doi.org/10.1007/s10071-011-0418-1

Geissmann, T. (1984). Inheritance of song parameters in the gibbon song, analysed in 2 hybrid gibbons (Hylobates pileatus x H.lar). Folia Primatologica, 42(3-4), 216-235. https://doi.org/10.1159/000156165

Genty, E. (2019). Vocal-gestural combinations in infant bonobos: new insights into signal functional specificity. Animal Cognition, 22(4), 505-518. https://doi.org/10.1007/s10071019-01267-0

Genty, E., Breuer, T., Hobaiter, C., \& Byrne, R. W. (2009). Gestural communication of the gorilla (Gorilla gorilla): repertoire, intentionality and possible origins. Animal Cognition, 12(3), 527-546. https://doi.org/10.1007/s10071-009-0213-4

Genty, E., Clay, Z., Hobaiter, C., \& Zuberbühler, K. (2014). Multi-modal use of a socially directed call in bonobos. PloS One, 9(1), e84738. https://doi.org/https://doi.org/10.1371/journal.pone.0084738

Genty, E., Neumann, C., \& Zuberbühler, K. (2015). Complex patterns of signalling to convey different social goals of sex in bonobos, Pan paniscus. Scientific Reports, 5(16135), 113.

Genty, E., \& Zuberbühler, K. (2014). Spatial reference in a bonobo gesture. Current Biology, 24(14), 1601-1605. https://doi.org/10.1016/J.CUB.2014.05.065

Genty, E., \& Zuberbühler, K. (2015). Iconic gesturing in bonobos. Communicative \& Integrative Biology, 8(1), e992742. https://doi.org/10.4161/19420889.2014.992742

Gouzoules, S., Gouzoules, H., \& Marler, P. (1984). Rhesus monkey (Macaca mulatta) screams: Representational signalling in the recruitment of agonistic aid. Animal 
Behaviour, 32(1), 182-193. https://doi.org/10.1016/S0003-3472(84)80336-X

Graham, K. E., Hobaiter, C., Ounsley, J., Furuichi, T., \& Byrne, R. W. (2018). Bonobo and chimpanzee gestures overlap extensively in meaning. PLOS Biology, 16(2), e2004825. https://doi.org/10.1371/journal.pbio.2004825

Graham, K. E., Wilke, C., Lahiff, N. J., \& Slocombe, K. E. (2019). Scratching beneath the surface: intentionality in great ape signal production. Philosophical Transactions of the Royal Society B: Biological Sciences, 375(1789), 20180403.

https://doi.org/10.1098/rstb.2018.0403

Grandjean, D., Bänziger, T., \& Scherer, K. R. (2006). Intonation as an interface between language and affect. Progress in Brain Research, 156, 235-247.

https://doi.org/10.1016/S0079-6123(06)56012-1

Gross, J. J., \& Levenson, R. W. (1997). Hiding feelings: The acute effects of inhibiting negative and positive emotion. Journal of Abnormal Psychology, 106(1), 95-103. https://doi.org/10.1037/0021-843X.106.1.95

Gruber, T., \& Grandjean, D. (2017). A comparative neurological approach to emotional expressions in primate vocalizations. Neuroscience \& Biobehavioral Reviews, 73, 182 190. https://doi.org/10.1016/J.NEUBIOREV.2016.12.004

Gruber, T., \& Zuberbühler, K. (2013). Vocal recruitment for joint travel in wild chimpanzees. PLoS ONE, 8(9), e76073. https://doi.org/10.1371/journal.pone.0076073

Gruber, T., Zuberbühler, K., Clement, F., \& van Schaik, C. (2015). Apes have culture but may not know that they do. Frontiers in Psychology, 6, 91. https://doi.org/10.3389/fpsyg.2015.00091

Halina, M., Rossano, F., \& Tomasello, M. (2013). The ontogenetic ritualization of bonobo gestures. Animal Cognition, 16, 653-666. https://doi.org/10.1007/s10071-013-0601-7

Hammerschmidt, K., \& Fischer, J. (2008). Constraints in primate vocal production. In K. Oller \& U. Griebel (Eds.), The evolution of communicative creativity: From fixed signals to contextual flexibility (pp. 93-119). Cambridge MA: MIT Press.

Haney, M., \& Miczek, K. A. (1993). Ultrasounds during agonistic interactions between female 
rats (Rattus norvegicus). Journal of Comparative Psychology, 107(4), 373-379. https://doi.org/10.1037/0735-7036.107.4.373

Hanya, G. (2009). Effects of food type and number of feeding sites in a tree on aggression during feeding in wild Macaca fuscata. International Journal of Primatology, 30(4), 569581. https://doi.org/10.1007/s10764-009-9361-2

Heesen, R., Bangerter, A., Zuberbühler, K., Iglesias, K., Rossano, F., Guéry, J. P., \& Genty, E. (2020). Bonobos engage in joint commitment. Science Advances, 6, eabd1306. https://doi.org/DOI: 10.1126/sciadv.abd1306

Heesen, R., Genty, E., Rossano, F., Zuberbühler, K., \& Bangerter, A. (2017). Social play as joint action: A framework to study the evolution of shared intentionality as an interactional achievement. Learning and Behavior, 45(4), 390-405. https://doi.org/10.3758/s13420-017-0287-9

Heesen, R., Hobaiter, C., Ferrer-I-Cancho, R., \& Semple, S. (2019). Linguistic laws in chimpanzee gestural communication. Proceedings of the Royal Society B: Biological Sciences, 286(1896). https://doi.org/10.1098/rspb.2018.2900

Hobaiter, C., \& Byrne, R. W. (2011a). Serial gesturing by wild chimpanzees: its nature and function for communication. Animal Cognition, 14(6), 827-838. https://doi.org/10.1007/s10071-011-0416-3

Hobaiter, C., \& Byrne, R. W. (2011b). The gestural repertoire of the wild chimpanzee. Animal Cognition, 14(5), 745-767. https://doi.org/10.1007/s10071-011-0409-2

Hobaiter, C., \& Byrne, R. W. (2012). Gesture use in consortship: wild chimpanzees' use of gesture for an 'evolutionarily urgent'purpose. In S. Pika \& K. Liebal (Eds.), Development in Primate Gesture Research (pp. 129-146). Amsterdam: John Benjamins Press.

Hobaiter, C., \& Byrne, R. W. (2014). The meanings of chimpanzee gestures. Current Biology, 24(14), 1596-1600. https://doi.org/10.1016/j.cub.2014.05.066

Hobaiter, C., Byrne, R. W., \& Zuberbühler, K. (2017). Wild chimpanzees' use of single and combined vocal and gestural signals. Behavioral Ecology and Sociobiology, 71(6), 96. https://doi.org/10.1007/s00265-017-2325-1 
Hobaiter, C., Leavens, D. A., \& Byrne, R. W. (2014). Deictic gesturing in wild chimpanzees (Pan troglodytes)? Some possible cases. Journal of Comparative Psychology, 128(1), 82-87. https://doi.org/10.1037/a0033757

Hopkins, W., Taglialatela, J., \& Leavens, W. (2011). Do chimpanzees have voluntary control of their facial expressions and vocalizations? In A. Vilain, J.-L. Schwartz, C. Abry, \& J. Vauclair (Eds.), Primate communication and human language - vocalization, gestures, imitation and deixis in humans and non-humans (pp. 71-88). Amsterdam, The Netherlands: John Benjamins Publishing Company.

Hostetter, A. B., Cantero, M., \& Hopkins, W. D. (2001). Differential use of vocal and gestural communication by chimpanzees (Pan troglodytes) in response to the attentional status of a human (Homo sapiens). Journal of Comparative Psychology, 115(4), 337-343. https://doi.org/10.1037/0735-7036.115.4.337

loannou, S., Gallese, V., \& Merla, A. (2014). Thermal infrared imaging in psychophysiology: Potentialities and limits. Psychophysiology, 51(10), 951-963. https://doi.org/10.1111/psyp.12243

Jürgens, U., Maurus, M., Ploog, D., \& Winter, P. (1967). Vocalization in the squirrel monkey (Saimiri sciureus) elicited by brain stimulation. Experimental Brain Research, 4(2), 114117. https://doi.org/10.1007/BF00240356

Juslin, P. N., Laukka, P., \& Bänziger, T. (2018). The mirror to our soul? Comparisons of spontaneous and posed vocal expression of emotion. Journal of Nonverbal Behavior, 42(1), 1-40. https://doi.org/10.1007/s10919-017-0268-x

Kano, F., Hirata, S., Deschner, T., Behringer, V., \& Call, J. (2016). Nasal temperature drop in response to a playback of conspecific fights in chimpanzees: A thermo-imaging study. Physiology \& Behavior, 155, 83-94. https://doi.org/10.1016/J.PHYSBEH.2015.11.029

Kret, M. E. (2015). Emotional expressions beyond facial muscle actions. A call for studying autonomic signals and their impact on social perception. Frontiers in Psychology, 6, 711. https://doi.org/10.3389/fpsyg.2015.00711 
Kret, M. E., Prochazkova, E., Sterck, E. H. M., \& Clay, Z. (2020). Emotional expressions in human and non-human great apes. Neuroscience \& Biobehavioral Reviews. https://doi.org/10.1016/j.neubiorev.2020.01.027

Kunzmann, U., Kupperbusch, C. S., \& Levenson, R. W. (2005). Behavioral Inhibition and Amplification During Emotional Arousal: A Comparison of Two Age Groups. Psychology and Aging, 20(1), 144-158. https://doi.org/10.1037/0882-7974.20.1.144

Leavens, D. A., Hopkins, W. D., \& Bard, K. A. (1996). Indexical and referential pointing in chimpanzees (Pan troglodytes). Journal of Comparative Psychology, 110(4), 346-353. https://doi.org/10.1037/0735-7036.110.4.346

Leavens, D. A., Hopkins, W. D., \& Thomas, R. K. (2004). Referential communication by chimpanzees (Pan troglodytes). Journal of Comparative Psychology, 118(1), 48-57. https://doi.org/10.1037/0735-7036.118.1.48

Leavens, D. A., Hostetter, A. B., Wesley, M. J., \& Hopkins, W. D. (2004). Tactical use of unimodal and bimodal communication by chimpanzees, Pan troglodytes. Animal Behaviour, 67(3), 467-476. https://doi.org/10.1016/J.ANBEHAV.2003.04.007

Leavens, D. A., Russell, J. L., \& Hopkins, W. D. (2005). Intentionality as measured in the persistence and elaboration of communication by chimpanzees (Pan troglodytes). Child Development, 76(1), 291-306. https://doi.org/10.1111/j.1467-8624.2005.00845.x

Liebal, K., Call, J., \& Tomasello, M. (2004). Use of gesture sequences in chimpanzees. American Journal of Primatology, 64(4), 377-396. https://doi.org/10.1002/ajp.20087

Liebal, K., Call, J., Tomasello, M., \& Pika, S. (2004). To move or not to move: How apes adjust to the attentional state of others. Interaction Studies, 5(2), 199-219. https://doi.org/10.1075/is.5.2.03lie

Liebal, K., \& Oña, L. (2018). Mind the gap - moving beyond the dichotomy between intentional gestures and emotional facial and vocal signals of nonhuman primates. Interaction Studies. Social Behaviour and Communication in Biological and Artificial Systems, 19(1-2), 121-135. https://doi.org/10.1075/is.17040.lie

Liebal, K., Waller, B. M., Slocombe, K. E., \& Burrows, A. M. (2013). Primate communication: 
A multimodal approach. Cambridge University Press.

Maiese, M. (2014). How can emotions be both cognitive and bodily? Phenomenology and the Cognitive Sciences, 13(4), 513-531. https://doi.org/10.1007/s11097-014-9373-z

Marler, P., \& Evans, C. (2008). Bird calls: just emotional displays or something more? Ibis, 138(1), 26-33. https://doi.org/10.1111/j.1474-919X.1996.tb04310.x

Marler, P., Evans, S., \& Hauser, M. (1992). Animal signals: Motivational, referential, or both? In H. Papousek, U. Jürgens, \& M. Papoušek (Eds.), Nonverbal vocal communication: Comparative and developmental approaches (pp. 66-86). Cambridge: Cambridge University Press.

Marshall-Pescini, S., Ceretta, M., \& Prato-Previde, E. (2014). Do domestic dogs understand human actions as goal-directed? PLoS ONE, 9(9), e106530. https://doi.org/10.1371/journal.pone.0106530

Massen, J. J. M., Behrens, F., Martin, J. S., Stocker, M., \& Brosnan, S. F. (2019). A comparative approach to affect and cooperation. Neuroscience \& Biobehavioral Reviews, 107, 370-387. https://doi.org/10.1016/J.NEUBIOREV.2019.09.027

Mazzini, F., Townsend, S. W., Virányi, Z., \& Range, F. (2013). Wolf howling is mediated by relationship quality rather than underlying emotional stress. Current Biology, 23(17), 1677-1680. https://doi.org/10.1016/J.CUB.2013.06.066

Melis, A. P., \& Tomasello, M. (2019). Chimpanzees (Pan troglodytes) coordinate by communicating in a collaborative problem-solving task. Proceedings of the Royal Society B: Biological Sciences, 286(1901), 20190408.

https://doi.org/10.1098/rspb.2019.0408

Meyer, D., Hodges, J. K., Rinaldi, D., Wijaya, A., Roos, C., \& Hammerschmidt, K. (2012). Acoustic structure of male loud-calls support molecular phylogeny of Sumatran and Javanese leaf monkeys (genus Presbytis). BMC Evolutionary Biology, 12(1), 16. https://doi.org/10.1186/1471-2148-12-16

Namba, S., Kabir, R. S., Miyatani, M., \& Nakao, T. (2018). Dynamic displays enhance the ability to discriminate genuine and posed facial expressions of emotion. Frontiers in 
Psychology, 9, 672. https://doi.org/10.3389/fpsyg.2018.00672

Nishida, T. (1997). Sexual behavior of adult male chimpanzees of the Mahale Mountains national park, Tanzania. Primates, 38(4), 379-398. https://doi.org/10.1007/BF02381879

Ochsner, K. N., \& Gross, J. J. (2005). The cognitive control of emotion. Trends in Cognitive Sciences, 9(5), 242-249. https://doi.org/10.1016/J.TICS.2005.03.010

Owren, M. J., Amoss, R. T., \& Rendall, D. (2011). Two organizing principles of vocal production: Implications for nonhuman and human primates. American Journal of Primatology, 73(6), 530-544. https://doi.org/10.1002/ajp.20913

Owren, M. J., \& Rendall, D. (1997). An affect-conditioning model of nonhuman primate vocal signaling (pp. 299-346). Springer, Boston, MA. https://doi.org/10.1007/978-1-48991745-4_10

Palagi, E., Antonacci, D., \& Cordoni, G. (2007). Fine-tuning of social play in juvenile lowland gorillas (Gorilla gorilla gorilla). Developmental Psychobiology, 49(4), 433-445. https://doi.org/10.1002/dev.20219

Palagi, E., Burghardt, G. M., Smuts, B., Cordoni, G., Dall'Olio, S., Fouts, H. N., ... Pellis, S. M. (2015). Rough-and-tumble play as a window on animal communication. Biological Reviews, 91(2), 311-327. https://doi.org/10.1111/brv.12172

Palagi, E., Norscia, I., \& Spada, G. (2014). Relaxed open mouth as a playful signal in wild ring-tailed lemurs. American Journal of Primatology, 76(11), 1074-1083. https://doi.org/10.1002/ajp.22294

Panksepp, J. (2011). Cross-species affective neuroscience decoding of the primal affective experiences of humans and related animals. PLoS ONE, 6(9), e21236. https://doi.org/10.1371/journal.pone.0021236

Parr, L. (2001). Cognitive and physiological markers of emotional awareness in chimpanzees (Pan troglodytes). Animal Cognition, 4(3-4), 223-229. https://doi.org/10.1007/s100710100085

Parr, L., Cohen, M., \& Waal, F. de. (2005). Influence of social context on the use of blended and graded facial displays in chimpanzees. International Journal of Primatology, 26(1), 
73-103. https://doi.org/10.1007/s10764-005-0724-z

Parr, L., Hopkins, W. D., \& DeWaal, F. B. M. (1998). The perception of facial expressions by chimpanzees, Pan troglodytes. Evolution of Communication, 2(1), 1-23.

https://doi.org/10.1075/eoc.2.1.02par

Parr, L., \& Waller, B. M. (2006). Understanding chimpanzee facial expression: insights into the evolution of communication. Social Cognitive and Affective Neuroscience, 1(3), 221-228. https://doi.org/10.1093/scan/nsl031

Parr, L., Waller, B. M., Burrows, A. M., Gothard, K. M., \& Vick, S. J. (2010). MaqFACS: A muscle-based facial movement coding system for the rhesus macaque. American Journal of Physical Anthropology, 143(4), 625-630. https://doi.org/10.1002/ajpa.21401

Parr, L., Waller, B. M., \& Heintz, M. (2008). Facial expression categorization by chimpanzees using standardized stimuli. Emotion, 8(2), 216-231. https://doi.org/10.1037/1528-3542.8.2.216

Parr, L., Waller, B. M., \& Vick, S. J. (2007). New developments in understanding emotional facial signals in chimpanzees. Current Directions in Psychological Science, 16(3), 117122. https://doi.org/10.1111/j.1467-8721.2007.00487.x

Pellis, S. M., \& Pellis, V. C. (1996). On knowing it's only play: The role of play signals in play fighting. Aggression and Violent Behavior, 1(3), 249-268. https://doi.org/10.1016/13591789(95)00016-X

Pika, S., \& Bugnyar, T. (2011). The use of referential gestures in ravens (Corvus corax) in the wild. Nature Communications, 2(1), 560. https://doi.org/10.1038/ncomms1567

Pika, S., \& Mitani, J. C. (2009). The directed scratch: Evidence for a referential gesture in chimpanzees? In R. Botha \& C. Knight (Eds.), The prehistory of language (pp. 166180). Oxford, UK: Oxford University Press.

Pollick, A. S., \& De Waal, F. B. M. (2007). Ape gestures and language evolution. Proceedings of the National Academy of Sciences, 104(19), 8184-8189.

Rendall, D., Rodman, P. S., \& Emond, R. E. (1996). Vocal recognition of individuals and kin in free-ranging rhesus monkeys. Animal Behaviour, 51(5), 1007-1015. 
https://doi.org/10.1006/ANBE.1996.0103

Robbins, M. M. (2008). Feeding competition and agonistic relationships among Bwindi gorilla beringei. International Journal of Primatology, 29(4), 999-1018. https://doi.org/10.1007/s10764-008-9275-4

Romanski, L. M., Averbeck, B. B., \& Diltz, M. (2005). Neural representation of vocalizations in the primate ventrolateral prefrontal cortex. Journal of Neurophysiology, 93(2), 734747. https://doi.org/10.1152/jn.00675.2004

Russell, J. A., Bachorowski, J.-A., \& Fernández-Dols, J.-M. (2003). Facial and vocal expressions of emotion. Annual Review of Psychology, 54(1), 329-349.

https://doi.org/10.1146/annurev.psych.54.101601.145102

Sander, D. (2013). Models of emotion: The affective neuroscience approach. In J. Armony \& P. Vuilleumier (Eds.), The Cambridge handbook of human affective neuroscience (pp. 5-53). Cambridge: Cambridge University Press.

Scarantino, A., \& Clay, Z. (2015). Contextually variable signals can be functionally referential. Animal Behaviour, 100(100), e1-e8. https://doi.org/10.1016/j.anbehav.2014.08.017

Scheider, L., Waller, B. M., Oña, L., Burrows, A. M., \& Liebal, K. (2016). Social use of facial expressions in hylobatids. PLOS ONE, 11(3), e0151733.

https://doi.org/10.1371/journal.pone.0151733

Schel, A. M., Townsend, S. W., Machanda, Z., Zuberbühler, K., \& Slocombe, K. E. (2013). Chimpanzee alarm call production meets key criteria for intentionality. PLoS ONE, 8(10), e76674. https://doi.org/10.1371/journal.pone.0076674

Scherer, K. R. (1986). Vocal affect expression: A review and a model for future research. Psychological Bulletin, 99(2), 143-165. https://doi.org/10.1037/0033-2909.99.2.143

Scherer, K. R. (2013). Vocal markers of emotion: Comparing induction and acting elicitation. Computer Speech \& Language, 27(1), 40-58.

https://doi.org/10.1016/J.CSL.2011.11.003

Seyfarth, R. M., \& Cheney, D. L. (2003). Meaning and emotion in animal vocalizations. 
Annals of the New York Academy of Sciences, 1000, 32-55.

https://doi.org/10.1196/annals.1280.004

Seyfarth, R. M., \& Cheney, D. L. (2017). Precursors to language: Social cognition and pragmatic inference in primates. Psychonomic Bulletin \& Review, 24(1), 79-84. https://doi.org/10.3758/s13423-016-1059-9

Seyfarth, R. M., Cheney, D. L., Bergman, T., Fischer, J., Zuberbühler, K., \& Hammerschmidt, K. (2010). The central importance of information in studies of animal communication. Animal Behaviour, 80(1), 3-8. https://doi.org/10.1016/J.ANBEHAV.2010.04.012

Seyfarth, R. M., Cheney, D. L., \& Marler, P. (1980). Vervet monkey alarm calls: Semantic communication in a free-ranging primate. Animal Behaviour, 28(4), 1070-1094. https://doi.org/10.1016/S0003-3472(80)80097-2

Siegel, E. H., Sands, M. K., Van den Noortgate, W., Condon, P., Chang, Y., Dy, J., ... Barrett, L. F. (2018). Emotion fingerprints or emotion populations? A meta-analytic investigation of autonomic features of emotion categories. Psychological Bulletin, 144(4), 343-393. https://doi.org/10.1037/bul0000128

Slocombe, K., Kaller, T., Call, J., \& Zuberbühler, K. (2010). Chimpanzees extract social information from agonistic screams. PLoS ONE, 5(7), e11473. https://doi.org/10.1371/journal.pone.0011473

Slocombe, K., Townsend, S. W., \& Zuberbühler, K. (2009). Wild chimpanzees (Pan troglodytes schweinfurthii) distinguish between different scream types: evidence from a playback study. Animal Cognition, 12(3), 441-449. https://doi.org/10.1007/s10071-0080204-x

Slocombe, K., \& Zuberbühler, K. (2005). Agonistic screams in wild chimpanzees (Pan troglodytes schweinfurthii) vary as a function of social role. Journal of Comparative Psychology, 119(1), 67-77. https://doi.org/10.1037/0735-7036.119.1.67

Slocombe, K., \& Zuberbühler, K. (2006). Food-associated calls in chimpanzees: responses to food types or food preferences? Animal Behaviour, 72(5), 989-999. 
https://doi.org/10.1016/J.ANBEHAV.2006.01.030

Slocombe, K., \& Zuberbühler, K. (2007). Chimpanzees modify recruitment screams as a function of audience composition. Proceedings of the National Academy of Sciences of the United States of America, 104(43), 17228-17233.

https://doi.org/10.1073/pnas.0706741104

Smith, P. K., \& Boulton, M. (1990). Rough-and-tumble play, aggression and dominance: Perception and behaviour in children's encounters. Human Development, 33(4-5), 271-282. https://doi.org/DOI:10.1159/000276524

Tamir, D. I., Thornton, M. A., Contreras, J. M., \& Mitchell, J. P. (2016). Neural evidence that three dimensions organize mental state representation: Rationality, social impact, and valence. Proceedings of the National Academy of Sciences of the United States of America, 113(1), 194-199. https://doi.org/10.1073/pnas.1511905112

Tattersall, G. J. (2016). Infrared thermography: A non-invasive window into thermal physiology. Comparative Biochemistry and Physiology Part A: Molecular \& Integrative Physiology, 202, 78-98. https://doi.org/10.1016/J.CBPA.2016.02.022

Thinh, V. N., Hallam, C., Roos, C., \& Hammerschmidt, K. (2011). Concordance between vocal and genetic diversity in crested gibbons. BMC Evolutionary Biology, 11(1), 36. https://doi.org/10.1186/1471-2148-11-36

Tomasello, M. (2008). Origins of human communication. MIT Press. Retrieved from https://books.google.com/books?id=T3bqzle3mAEC

Townsend, S. W., Koski, S. E., Byrne, R. W., Slocombe, K., Bickel, B., Boeckle, M., ... Manser, M. B. (2017). Exorcising Grice's ghost: an empirical approach to studying intentional communication in animals. Biological Reviews, 92(3), 1427-1433. https://doi.org/10.1111/brv.12289

Townsend, S. W., \& Manser, M. B. (2013). Functionally referential communication in mammals: The past, present and the future. Ethology, 119(1), 1-11. https://doi.org/10.1111/eth.12015

Tsao, D. Y., Moeller, S., \& Freiwald, W. A. (2008). Comparing face patch systems in 
macaques and humans. Proceedings of the National Academy of Sciences of the United States of America, 105(49), 19514-19519.

https://doi.org/10.1073/pnas.0809662105

Turner, J. H. (1996). The Evolution of Emotions in Humans: A Darwinian-Durkheimian Analysis. Journal for the Theory of Social Behaviour, 26(1), 1-33.

https://doi.org/10.1111/j.1468-5914.1996.tb00283.x

Vail, A. L., Manica, A., \& Bshary, R. (2013). Referential gestures in fish collaborative hunting. Nature Communications, 4(1), 1765. https://doi.org/10.1038/ncomms2781

Waller, B. M., Caeiro, C. C., \& Davila-Ross, M. (2015). Orangutans modify facial displays depending on recipient attention. PeerJ, 3, e827. https://doi.org/10.7717/peerj.827

Waller, B. M., \& Cherry, L. (2012). Facilitating play through communication: Significance of teeth exposure in the gorilla play face. American Journal of Primatology, 74(2), 157164. https://doi.org/10.1002/ajp.21018

Waller, B. M., \& Dunbar, R. I. M. (2005). Differential behavioural effects of silent bared teeth display and relaxed open mouth display in chimpanzees (Pan troglodytes). Ethology, 111(2), 129-142. https://doi.org/10.1111/j.1439-0310.2004.01045.x

Waller, B. M., Lembeck, M., Kuchenbuch, P., Burrows, A. M., \& Liebal, K. (2012).

GibbonFACS: A muscle-based facial movement coding system for Hylobatids. International Journal of Primatology, 33(4), 809-821. https://doi.org/10.1007/s10764$012-9611-6$

Waller, B. M., Liebal, K., Burrows, A. M., \& Slocombe, K. E. (2013). How can a multimodal approach to primate communication help us understand the evolution of communication? Evolutionary Psychology, 11(3), 147470491301100. https://doi.org/10.1177/147470491301100305

Waller, B. M., Whitehouse, J., \& Micheletta, J. (2016). Macaques can predict social outcomes from facial expressions. Animal Cognition, 19(5), 1031-1036. https://doi.org/10.1007/s10071-016-0992-3

Wharton, T. (2009). Pragmatics and non-verbal communication. Cambridge: Cambridge 
University Press.

Wheeler, B. C., \& Fischer, J. (2015). The blurred boundaries of functional reference: a response to Scarantino \&amp; Clay. Animal Behaviour, 100(100), e9-e13. https://doi.org/10.1016/j.anbehav.2014.11.007

Wheeler, B. C., Tiddi, B., \& Heistermann, M. (2014). Competition-induced stress does not explain deceptive alarm calling in tufted capuchin monkeys. Animal Behaviour, 93, 4958. https://doi.org/10.1016/J.ANBEHAV.2014.04.016

Zajonc, R. B. (1965). Social Facilitation. Science, 149(3681), 269-274. https://doi.org/10.1126/science.149.3681.269

Zuberbühler, K. (2003). Referential signaling in non-human primates: Cognitive precursors and limitations for the evolution of language. In Slater P. J. B., Rosenblatt J. S., C. T. Snowdon, \& T. J. Roper (Eds.), Advances in the study of behavior (33rd ed., pp. 265307). Elsevier Academic Press. https://doi.org/10.1016/S0065-3454(03)33006-2

Zuberbühler, K. (2008). Audience effects. Current Biology, 18(5), R189-R190. https://doi.org/10.1016/j.cub.2007.12.041

Zuberbühler, K., Cheney, D. L., \& Seyfarth, R. M. (1999). Conceptual semantics in a nonhuman primate. Journal of Comparative Psychology, 113(1), 33-42. https://doi.org/10.1037/0735-7036.113.1.33 